\title{
Short Term Outcome of Bare Metal Stent vs Covered Stent in Treatment of Symptomatic Central Venous Occlusion in Association with Functioning upper Limb Arterio-Venous Access
}

\author{
Abdulrahman Mohamed, ${ }^{1}$ MD; Amr Nabil, ${ }^{1}$ MD; Hamdy Abo Elneel, ${ }^{1}$ MD; Othman AboElsebaa ${ }^{2}$ \\ ${ }^{1}$ Department of Vascular Surgery, Ain Shams University, Egypt \\ ${ }^{2}$ Department of Vascular Surgery, Menia University, Egypt
} Aim: To assess the primary patency of the central veins of the upper limb after percutaneous transluminal balloon
angioplasty (PTA) with bare metal stent Vs covered stent.

Patients and methods: 26 patients having venous hypertension of the upper limb on regular hemodialysis at Ain Shams University Hospitals dialysis units and Menia University were included in the study from June 2016 till June 2017. Collected data were followed up till December 2018. Patients were divided randomly into two groups, Group A: 13 Patients who underwent balloon dilatation of completely occluded or more than $50 \%$ stenosed central veins with bare metal stent and Group B: 13 Patients who underwent balloon dilatation of completely occluded or more than $50 \%$ stenosed central veins with covered stent . The primary patency, assisted primary patency and secondary patency of these procedures were assessed in a period of 18 months.

Results: The technical success rate was $100 \%(n=26)$, 1ry stenting was done in $100 \%(n=26)$ of cases. The patency rate at 18 months after intervention was $69.2 \%$ primary assisted patency and $92.3 \%$ secondary patency in bare metal stent group while it was $100 \%$ both primary assisted and secondary patency at 18 months in covered stent group.

Conclusion: Percutaneous transluminal angioplasty with covered stent carries a higher patency rate in short term follow up. But more cases should have longer follow up time in multi centers.

Keywords: Venous hypertension, bare metal stent, covered stent, central veins, primary stenting of central veins, Chronic renal failure.

\section{Introduction}

Central venous occlusive disease associated with functioning upper limb arteriovenous access is a significant problem facing hemodialysis patients with incidence of $2 \%-40 \% .{ }^{1}$ Its clinical presentation ranges from upper limb, facial, or breast swelling up to compromised dialysis and possibility of loss of dialysis access or it can be asymptomatic. ${ }^{1}$

The etiology of such problem is thought to be either repeated percutaneous central venous catheter placement or turbulent high flow through central veins due to functioning access. ${ }^{2}$

Intervention is needed in $12 \%-13 \%$ of symptomatic central venous occlusive disease patients. ${ }^{3}$ Due to associated morbidity to surgical approach which has prolonged patency, endovascular solutions are the first line treatment reserving the surgical options for failed percutaneous procedures. ${ }^{4.5}$ Unfortunately, the immediate results of balloon angioplasty of occlusive lesions showed immediate elastic recoil in $50 \%$ of cases and bare metal stents have no advantage over balloon angioplasty as regard long term patency. ${ }^{6.7}$

Recently, stent graft placement has encouraging results in treatment of recurrent cephalic arch stenosis and arteriovenous graft venous end anastomosis stenosis due to combined benefits of such graft as regard being a barrier for intimal hyperplasia in addition to mechanical advantages of bare metal stent as well as safe and effective role of controlling bleeding. ${ }^{1.8-10}$

\section{Patients and methods}

This study was conducted on patients on regular haemodialysis at dialysis units of Ain Shams University hospitals and Menia Uneversity Hospitals. This is a prospective randomized study that was conducted upon patients on regular haemodialysis through an arteriovenous vascular access from June 2016 till June 2017. Collected data were followed up till December 2018.

Patients were divided randomly into two groups, Group A: 13 Patients who underwent balloon dilatation of completely occluded or more than 
$50 \%$ stenosed central veins with bare metal stent and Group B: 13 Patients who underwent balloon dilatation of completely occluded or more than $50 \%$ stenosed central veins with covered stent. The primary patency, assisted primary patency and secondary patency of these procedures were assessed in a period of 18 months.

The inclusion criteria of these patients were:

1. All patients aging $>18$ years.

2. Patients on haemodialysis for more than 3 months.

3. Increase of venous pressure resistance during haemodialysis (measured by the dialysis machine pressure transducer at the beginning of hemodialysis using 15 gauge needles at a blood flow of $200 \mathrm{ml} / \mathrm{min}$, measurements > 150 $\mathrm{mmHg}$ are considered abnormal).

4. Persistent or progressing entire limb swelling after creation of arterio-venous access.

5. Appearance of dilated chest veins after creation of arterio-venous access.

6. All included patients must have central venous occlusion or $>50$ stenosis on the ipsilateral upper limb of functioning arteriovenous access.

7. Patient's approval to be included in the study.

\section{The exclusion criteria were:}

1. Patients below 18 years .

2. Patients on haemodialysis for less than 3 months.

3. History of Upper limb DVT prior to AV access creation.

4. Presence of non central venous lesion.

5. Non Functioning arterio-venous access.

\section{Method of randomization:}

Every patient was given a number reflecting his order for intervention odd numbers in group $A$ and even numbers in group $B$

\section{Every patient was subjected to:}

1. History taking with especial attention to previous central venous catheterization.

2. Clinical examination with recording of the upper limb size (circumference).

3. Duplex Scanning and or CT angiography, if not feasible or inconclusive intraoperative direct angiography was done.

\section{Procedure:}

1. The procedure was done under local infiltration anesthesia with puncture of the arterlized vein or PTFE graft at mid arm of the affected site while the patient was in the supine position, some cases we need also retrograde femoral axis.

2. Seldinger technique was used with introduction of a $8-10 \mathrm{~F}$ (Prelude $\AA$, MeritMedical or

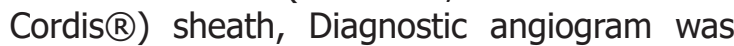
done to select the area for intervention using non ionic contrast media.

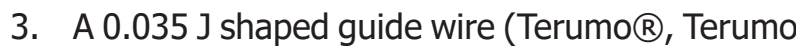
corporation) was manipulated to cross the lesion as much as possible distal to the lesion, this negotiation with the lesion was done by a combination of $5 F$ guiding catheter(Performa $\Re$, MeritMedical).

4. After crossing the lesion, the balloon was introduced. Balloons were from $12-16 \mathrm{~mm}$ in diameter with length of $40 \mathrm{~mm}$. The balloon catheter was advanced into position over the guide wire using fluoroscopy. The balloon was slowly inflated by diluted contrast solution under fluoroscopy, using an inflation device, or hand inflation.

5. Completion angiography was done for evaluation of angioplasty results. Followed by insertion of bare metal stent at the site of total occlusion in group $A$, and covered stent in group $B$.

6. Technical success was defined as improvement of luminal diameter of more than $50 \%$ or less than $30 \%$ residual stenosis (Figure 1).

7. Manual compression of the puncture site: immediately after removal of the sheath for 15 to 20 minutes (it was done immediately after the procedure).

8. Follow up was done every 3 months interval postoperatively till 18 months, in the form of clinical examination to assess improvement of symptoms.

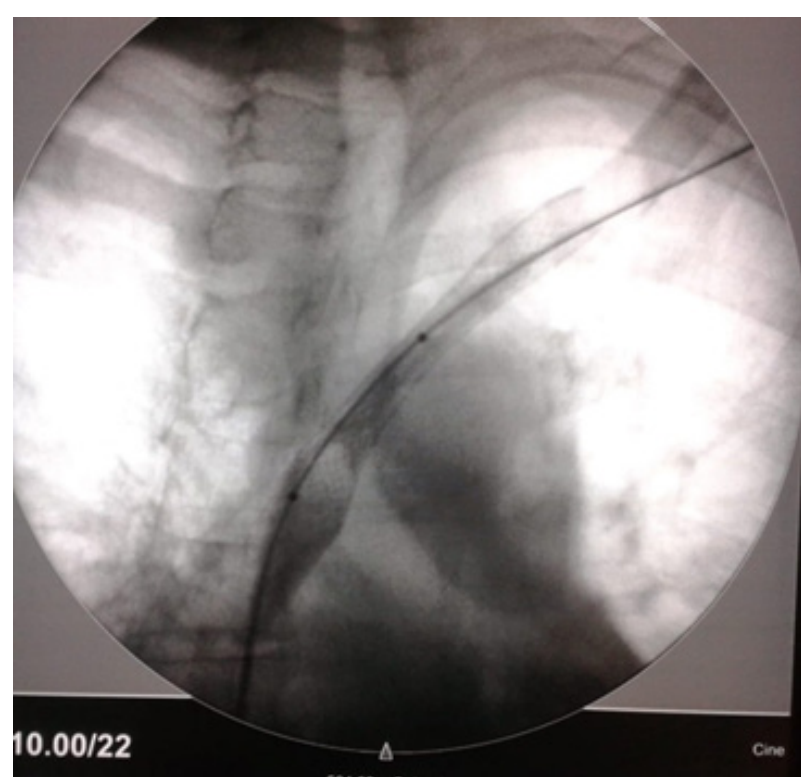

Fig 1: Left innominate baremetal stent.

\section{Results}

This study was conducted on 26 patients undergoing regular hemodialysis sessions at Ain Shams University Hospitals dialysis units and Menia university hospitals in the period from June 2016 till June 2017, collected data were followed up till 
December 2018.

The patients included in the study were 11 males versus 15 females with a percentage of $42.3 \%$ and
$57.7 \%$ respectively. The mean age of patients was $61.23 \pm 13.276 y e a r s$ other demographic data are shown in (Table 1).

Table 1: The following table shows patients' demographic data

\begin{tabular}{|c|c|c|c|c|}
\hline & & \multicolumn{2}{|c|}{ Stent type } & \multirow[t]{2}{*}{ P-value } \\
\hline & & Bare metal stent & Covered stent & \\
\hline \multirow{4}{*}{ Gender } & \multirow{2}{*}{ Male } & 5 & 6 & \multirow{4}{*}{$0.69^{*}$} \\
\hline & & $45.5 \%$ & $54.5 \%$ & \\
\hline & \multirow{2}{*}{ Female } & 8 & 7 & \\
\hline & & $53.3 \%$ & $46.7 \%$ & \\
\hline \multirow{4}{*}{ Smoking } & \multirow{2}{*}{ No } & 10 & 12 & \multirow{4}{*}{$0.27^{* *}$} \\
\hline & & $45.5 \%$ & $54.5 \%$ & \\
\hline & \multirow{2}{*}{ Yes } & 3 & 1 & \\
\hline & & $75.0 \%$ & $25.0 \%$ & \\
\hline \multirow{4}{*}{ Obesity } & \multirow{2}{*}{ No } & 10 & 10 & \multirow{4}{*}{$1^{* *}$} \\
\hline & & $50.0 \%$ & $50.0 \%$ & \\
\hline & \multirow{2}{*}{ Yes } & 3 & 3 & \\
\hline & & $50.0 \%$ & $50.0 \%$ & \\
\hline \multirow{4}{*}{ DM } & \multirow{2}{*}{ No } & 5 & 7 & \multirow{4}{*}{$0.43^{*}$} \\
\hline & & $41.7 \%$ & $58.3 \%$ & \\
\hline & \multirow{2}{*}{ Yes } & 8 & 6 & \\
\hline & & $57.1 \%$ & $42.9 \%$ & \\
\hline \multirow{4}{*}{ HTN } & \multirow{2}{*}{ No } & 3 & 8 & \multirow{4}{*}{$0.047^{*}$} \\
\hline & & $27.3 \%$ & $72.7 \%$ & \\
\hline & \multirow{2}{*}{ Yes } & 10 & 5 & \\
\hline & & $66.7 \%$ & $33.3 \%$ & \\
\hline \multirow{4}{*}{ ISHD } & No & 5 & 6 & \multirow{4}{*}{$0.69^{*}$} \\
\hline & & $45.5 \%$ & $54.5 \%$ & \\
\hline & Yes & 8 & 7 & \\
\hline & & $53.3 \%$ & $46.7 \%$ & \\
\hline \multirow{2}{*}{$\begin{array}{c}\text { Renal } \\
\text { Insufficiency }\end{array}$} & \multirow[t]{2}{*}{ Yes } & 13 & 13 & \multirow{2}{*}{ - } \\
\hline & & $50.0 \%$ & $50.0 \%$ & \\
\hline
\end{tabular}

Of the studied group, most of patients had previous history of central venous catheterization, all have thrill over the fistulae and all have dilated chest veins, the following (Table 2) demonstrate the clinical data between both groups. 


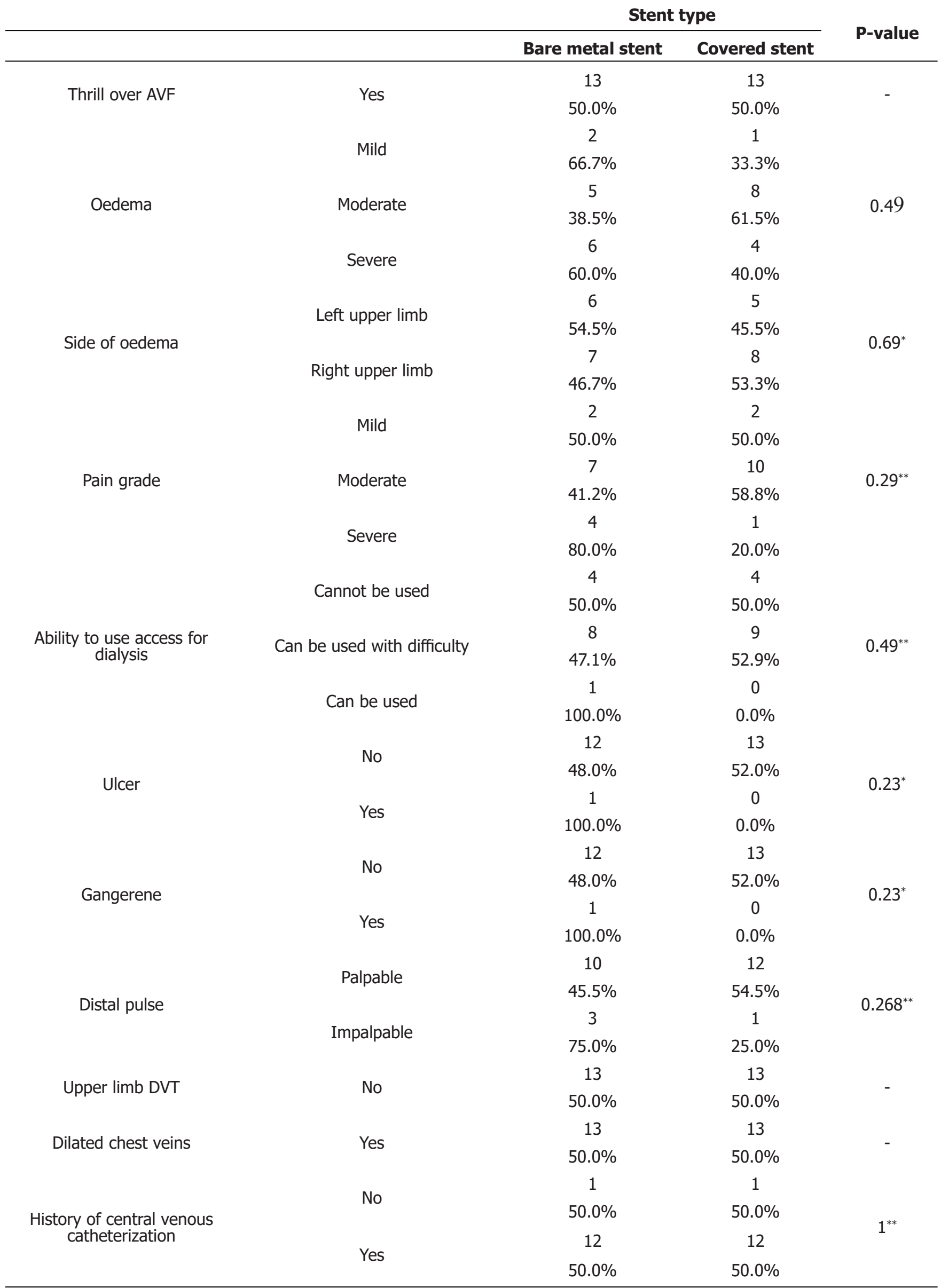


All patients were subjected to either duplex examination, CT venography or intaraoperative venogram to determine the location and degree of the lesion. The following (Table 3) describes these data and the endovascular details as wire type, balloon type and site of stenting.
Table 3: Demographics of the endovascular procedure

\begin{tabular}{|c|c|c|c|c|}
\hline \multirow{4}{*}{ Degree of stenosis } & & 11 & 12 & \multirow{4}{*}{$0.546^{* *}$} \\
\hline & Iotal occlusion & $47.8 \%$ & $52.2 \%$ & \\
\hline & \multirow{2}{*}{$>50 \%$ stenosis } & 2 & 1 & \\
\hline & & $66.7 \%$ & $33.3 \%$ & \\
\hline \multirow{6}{*}{ Site of stenosis } & \multirow{2}{*}{ Subclavian } & 2 & 1 & \multirow{6}{*}{$0.486^{* *}$} \\
\hline & & $66.7 \%$ & $33.3 \%$ & \\
\hline & \multirow{2}{*}{ Innominate } & 5 & 8 & \\
\hline & & $38.5 \%$ & $61.5 \%$ & \\
\hline & \multirow{2}{*}{ Innominate and Subclavian } & 6 & 4 & \\
\hline & & $60.0 \%$ & $40.0 \%$ & \\
\hline \multirow{4}{*}{ Access site } & \multirow{2}{*}{ Trans-access } & 12 & 11 & \multirow{4}{*}{$0.536^{* *}$} \\
\hline & & $52.2 \%$ & $47.8 \%$ & \\
\hline & \multirow{2}{*}{ both access and femoral vein } & 1 & 2 & \\
\hline & & $33.3 \%$ & $66.7 \%$ & \\
\hline \multirow{6}{*}{ Guidewire character } & \multirow{2}{*}{ Standard 0.035 hydrophilic guidewire } & 8 & 8 & \multirow{6}{*}{$0.422^{* *}$} \\
\hline & & $50.0 \%$ & $50.0 \%$ & \\
\hline & Stiff 0035 hydronhilic ayidewire & 4 & 2 & \\
\hline & 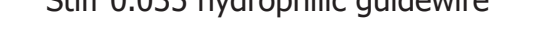 & $66.7 \%$ & $33.3 \%$ & \\
\hline & Standard 0018 auidewire & 1 & 3 & \\
\hline & searluar & $25.0 \%$ & $75.0 \%$ & \\
\hline \multirow{4}{*}{ Balloon type } & \multirow{2}{*}{ High pressure } & 13 & 13 & \multirow{4}{*}{-} \\
\hline & & $50.0 \%$ & $50.0 \%$ & \\
\hline & \multirow{2}{*}{ Subclavian } & 2 & 1 & \\
\hline & & $66.7 \%$ & $33.3 \%$ & \\
\hline \multirow{4}{*}{ Site of Stent } & \multirow{2}{*}{ Innominate } & 5 & 8 & \multirow{4}{*}{$0.486^{* *}$} \\
\hline & & $38.5 \%$ & $61.5 \%$ & \\
\hline & \multirow{2}{*}{ Innominate and Subclavian } & 6 & 4 & \\
\hline & & $60.0 \%$ & $40.0 \%$ & \\
\hline
\end{tabular}

Technical and procedural success were obtained with intact thrill, and decreased oedema and dilated chest veins (Table 4) and (Figure 2). 
Table 4: Postoperative outcomes between 2 groups

\begin{tabular}{|c|c|c|c|c|}
\hline \multirow{2}{*}{$\begin{array}{l}\text { Postoperative } \\
\text { thrill over AVF }\end{array}$} & \multirow{2}{*}{ Yes } & 13 & 13 & \multirow{2}{*}{-} \\
\hline & & $50.0 \%$ & $50.0 \%$ & \\
\hline \multirow{6}{*}{$\begin{array}{c}\text { Postoperative } \\
\text { oedema }\end{array}$} & \multirow{2}{*}{ Mild } & 2 & 2 & \multirow{6}{*}{$0.424^{* *}$} \\
\hline & & $50.0 \%$ & $50.0 \%$ & \\
\hline & \multirow{2}{*}{ Moderate } & 5 & 8 & \\
\hline & & $38.5 \%$ & $61.5 \%$ & \\
\hline & \multirow{2}{*}{ Severe } & 6 & 3 & \\
\hline & & $66.7 \%$ & $33.3 \%$ & \\
\hline \multirow{2}{*}{ Technical success } & \multirow{2}{*}{ Yes } & 13 & 13 & \multirow{2}{*}{-} \\
\hline & & $50.0 \%$ & $50.0 \%$ & \\
\hline \multirow{2}{*}{$\begin{array}{l}\text { Procedural suc- } \\
\text { cess }\end{array}$} & \multirow{2}{*}{ Yes } & 13 & 13 & \multirow{2}{*}{-} \\
\hline & & $50.0 \%$ & $50.0 \%$ & \\
\hline \multirow{4}{*}{$\begin{array}{l}\text { Postoperative } \\
\text { distal pulse }\end{array}$} & \multirow{2}{*}{ No } & 10 & 12 & \multirow{4}{*}{$0.268^{* *}$} \\
\hline & & $45.5 \%$ & $54.5 \%$ & \\
\hline & \multirow{2}{*}{ Yes } & 3 & 1 & \\
\hline & & $75.0 \%$ & $25.0 \%$ & \\
\hline \multirow{4}{*}{$\begin{array}{l}\text { Postop dilated } \\
\text { chest veins }\end{array}$} & \multirow{2}{*}{ Disappeared } & 11 & 9 & \multirow{4}{*}{$0.348^{* *}$} \\
\hline & & $55.0 \%$ & $45.0 \%$ & \\
\hline & \multirow{2}{*}{ Mild } & 2 & 4 & \\
\hline & & $33.3 \%$ & $66.7 \%$ & \\
\hline
\end{tabular}

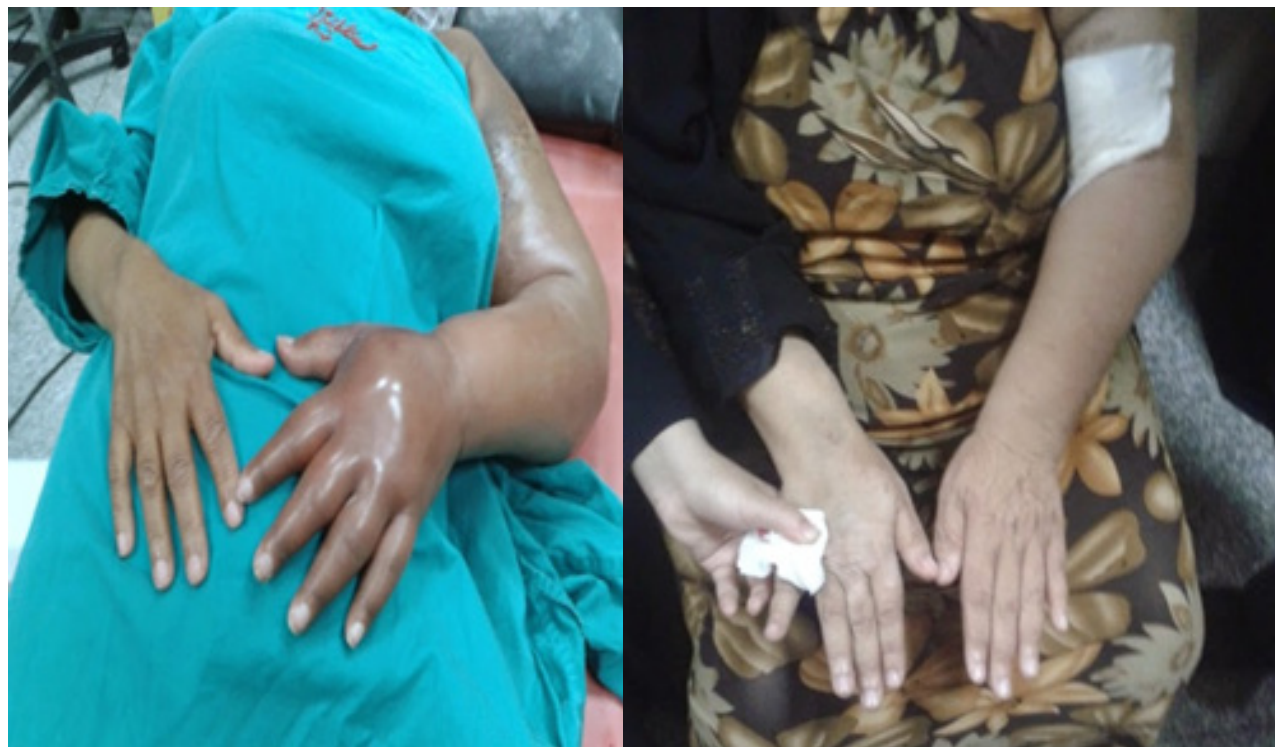

Fig 2: Left upper limb oedema pre and post-procedure (oedema subsides gradually within few days).

Follow up of these patients was done depending upon recurrence of symptoms including recurrence of upper limb swelling, presence of veins on anterior chest wall, and/or follow up duplex.

Primary patency rates were found to be $100 \%$ in the first 3months in both groups then decreased to be $84.6 \%, 61.5 \%, 23.1 \%$ and $23.1 \%$ at $6,9,12$ and 18 months respectively in the group of bare-metal stents, while in the group of covered stents primary patency was $100 \%, 92.3 \%, 76.9 \%$ and $69.2 \%$ at $6,9,12$ and 18 months respectively (Figure $\mathbf{3}$ ).
Primary assisted patency was found to be much lower in bare-metal stent group being $100 \%$ $100 \%, 76.9 \%$ and $69.2 \%$ at $6,9,12$ and 18 months respectively if compared by the group of covered stent which was $100 \%$ till 18 months (Figure 4).

The secondary patency was also lower in baremetal stent group being $100 \%, 92.3 \%$ and $92.3 \%$ at 9,12 and 18 months respectively compared to $100 \%$ patency at 18 months in the covered stent group (Table 5 ). 


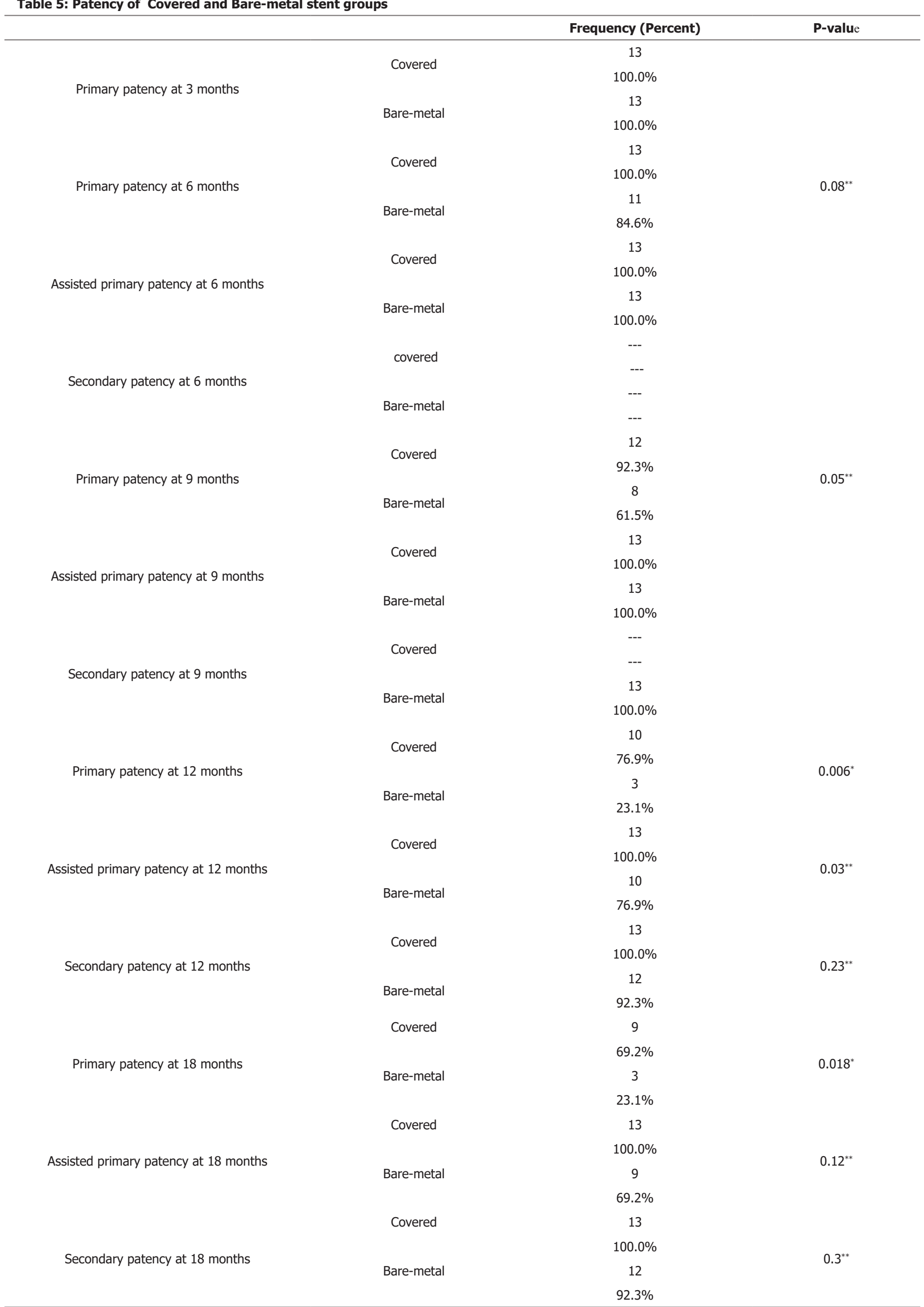




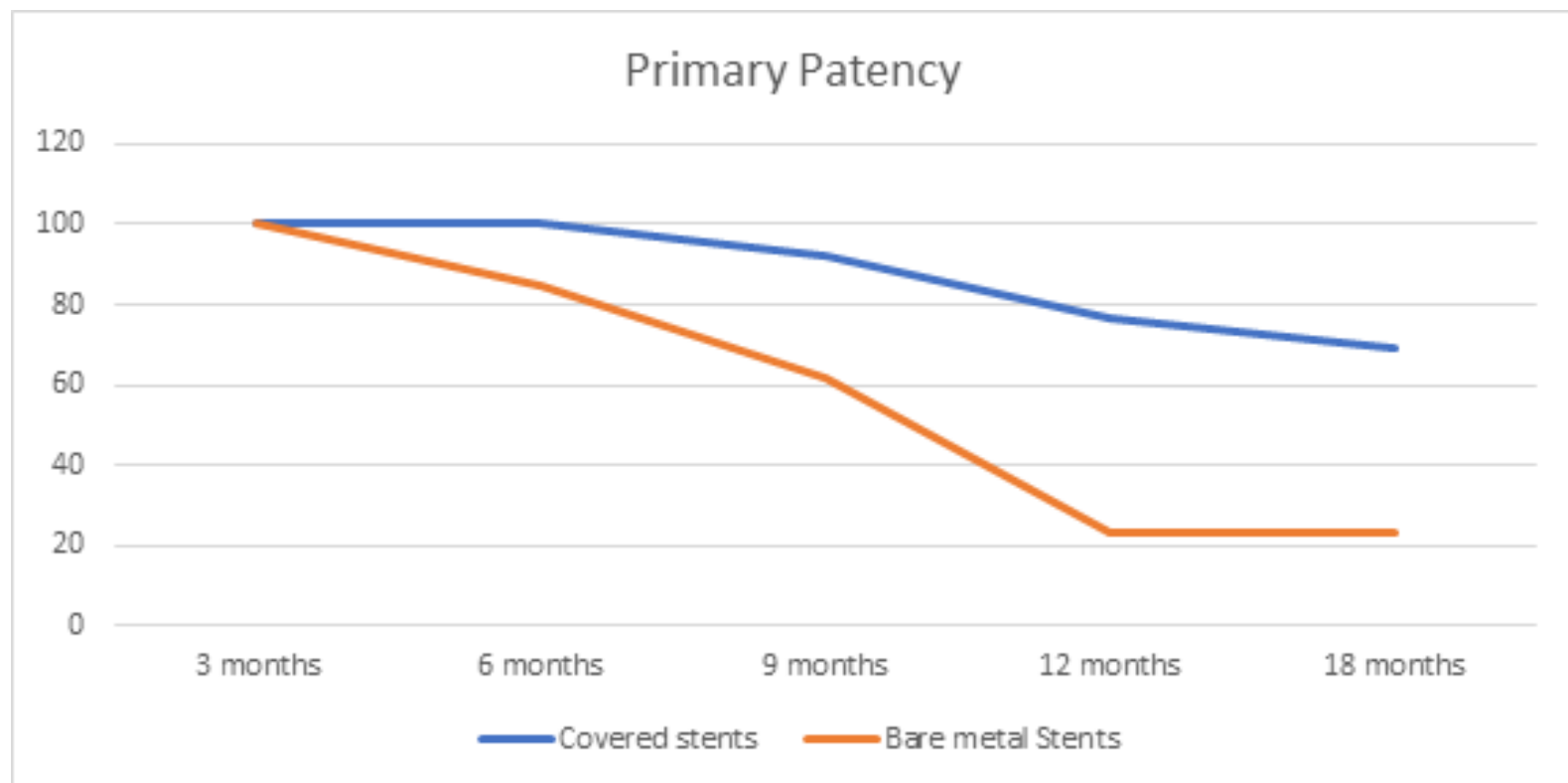

Fig 3: Primary patency of both groups.

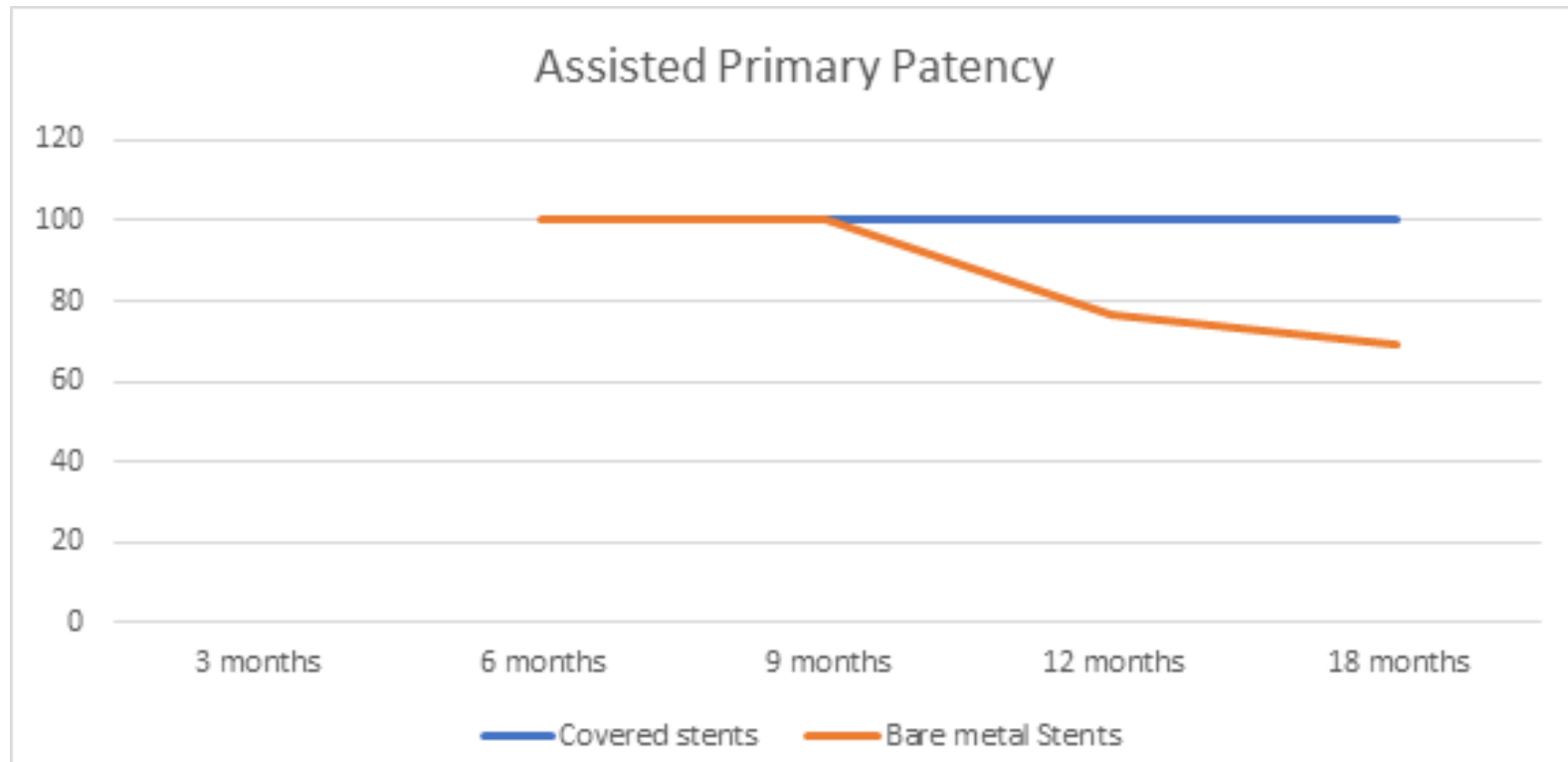

Fig 4: Assisted primary patency of both groups.

\section{Discussion}

The central venous occlusive disease carries a lot of access morbidities which necessitate active management in form of balloon angioplasty but the ideal treatment of occlusive lesion is currently under evaluation.

Recurrence after balloon angioplasty due to intimal hyperplasia or recoil is common with primary patency rates at 3, 6, 12 months are 58\%, 23\%$63 \%, 43 \%$ respectively. ${ }^{4.11 .12}$ Bare metal stent placement is subjected to in-stent stenosis because of intimal hyperplasia through fenestrations which does not improve patency rates. ${ }^{7.12}$ On the other hand, stent graft placement carries better patency rates at 9 months up to $100 \%$ based on few non randomized studies. ${ }^{13}$

In our study, results demonstrate better short term outcome with longer patency rates as the patency rate at 18 months after intervention was $69.2 \%$ primary assisted patency and $92.3 \%$ secondary patency in bare metal stent group while it was $100 \%$ both primary assisted and secondary patency at 18 months in covered stent group which suggest its use in occlusive type of lesions waiting for long term results that recommend stent graft placement. 


\section{Conclusion}

Percutaneous transluminal angioplasty with covered stent carry a higher patency rate in short term follow up. But more cases should have longer follow up time in multi centers.

\section{References}

1. Kundu S: Review of central venous disease in hemodialysis patients. $\boldsymbol{J}$ Vasc IntervRadiol. 2010; 21: 963-969.

2. Roy-Chaudhury P, Lee TC: Vascular stenosis: Biology and interventions. Curr Opin Nephrol Hypertens. 2007; 16: 516-522.

3. Bozof R, Katz M, Barker J, Allon M: Time to symptomatic vascular stenosis at different locations in patients with arteriovenous grafts. Semin Dial. 2008; 21: 285-288.

4. Mansour M, Kamper L, Altenberg A, Haage P: Radiological central vein treatment in vascular access. J Vasc Access. 2008; 9: 85-101.

5. Anaya-Ayala JE, Bellows PH, Ismail N, Cheema ZF, Naoum JJ, Bismuth J, et al: Surgical management of hemodialysis-related central venous occlusive disease: a treatment algorithm. Ann Vasc Surg. 2011; 25: 108-119.

6. Kim YC, Won JY, Choi SY, et al: Percutaneous treatment of central venous stenosis in hemodialysis patients: long term outcomes. Cardio-Vasc InterventRadiol. 2009; 32: 271-278.

7. Ozyer U, Harman A, Yildirim E, Aytekin C, Karakayali F, Boyvat F: Long- term results of angioplasty and stent placement for treatment of central venous obstructionin 126 hemodialysispatients:a ten year single center experience. AJR Am JRoentgenol. 2009; 193: 1672-1679.

8. Shemesh D, Goldin I, Zaghal I, Berlowitz D, Raveh D, Olsha O: Angio-plasty with stent graft versus bare stent for recurrent cephalic arch stenosis in autogenous arteriovenous access for hemodialysis: a pro- spective randomized clinical trial. J Vasc Surg. 2008; 48: 1524-1531.

9. Haskal ZJ, Trerotola S, Dolmatch B, et al: Stent graft versus balloon angioplasty for failing dialysis access grafts. N Engl J Med. 2010; 362: 494-503.

10. Anaya-Ayala JE, Charlton-Ouw KM, Kaiser CL, Peden EK: Successful emergency endovascular treatment for superior vena cava injury. Ann Vasc Surg. 2009;23: 139-141.

11. Surowiec SM, Fegley AJ, Tanski WJ, et al: Endovascular management of central venous stenosis in the hemodialysis patient: Results of percutaneous therapy. Vasc Endovasc Surg. 2004; 38: 549-554.

12. Kundu S: Review of central venous disease in hemodialysis patients. $\boldsymbol{J}$ Vasc Interv Radiol. 2010; 21: 963-968.

13. Kundu $S$, Modabber $M$, You JM, Tam $P$, Nagai G, Ting R: Use of PTFE stent grafts for hemodialysis-related central venous occlusions: intermediate-term results. Cardiovasc Intervent Radiol. 2011; 34:949-957. 